\title{
The Entrepreneurial Process Networks as a New Theoretical Framework for Understanding and Analyzing the Practice of Creating a New Business Venture
}

\author{
Mohammad Orsan Al-Zoubi, PhD \\ Department of Business Management, Faculty of Business \\ The University of Jordan
}

Received: May 4, 2016

doi:10.5296/jmr.v8i3.9449
Accepted: June 15, 2016 Published: July 1, 2016

URL: http://dx.doi.org/10.5296/jmr.v8i3.9449

\begin{abstract}
The major methodological gap is that most recent entrepreneurial studies are focusing on the causes or consequences of creating new business ventures rather than the process in which the entrepreneurship is generated, formulated, developed and implemented in the first place. Reviewing the extant literature has revealed that most studies of entrepreneurial process focused on two main different approaches: the entrepreneurial stages approach and the entrepreneurial networks approach. To bridge the gap between these different approaches this paper is aimed to introduce the Entrepreneurial Process Networks (EPN) as a new theoretical framework for understanding the effect of formal and informal networks on entrepreneurial process. EPN is derived from combining the advantages of the entrepreneurial process in stages (vertical) and the entrepreneurial networks approach (horizontal) which is located within a larger system idea of dynamic and interdependency. Our assumption here is that different formal and informal networks participate across entrepreneurial stages by influencing each other and giving accumulative outcomes for the whole entrepreneurial process. EPN would be a helpful methodology for future entrepreneurial research that enables an entrepreneur or practitioner to understand why the process of creating new business venture may succeed or fail to produce effective performance or predictable outcomes, as well as enabling the entrepreneur to start, develop and manage social networks as the holders to valuable resources such as: knowledge, information, skills and capital which entrepreneur really needs to achieve its objectives.
\end{abstract}




\section{Macrothink}

Journal of Management Research ISSN 1941-899X 2016, Vol. 8, No. 3

Keywords: entrepreneurship; entrepreneurial process; entrepreneurial stages approach; system idea; dynamic approach; interdependence approach; entrepreneurial networks approach. 


\section{Introduction}

In general, entrepreneurship is an instrument developed to create new innovative order in large systems such as economy, industry and social system. The process is a series of steps constructed in a systematic manner to transform an idea into a fully fledged firm, or course of actions or programs, or strategies intended to direct the attention of the entrepreneur toward ways of doing new innovative business (Muzyka, deKoning \& Churchill, 1997). Together the entrepreneurship and processes are developed to ensure that intentions or objectives of the entrepreneur lead to outcomes that are compatible with his new innovative views.

This paper aims to build a new theoretical framework for understanding and analyzing the process in which a new business venture is generated, formulated and implemented. This is done as an attempt to make the entrepreneur understand why such a complex process which involves different entrepreneurial stages and many social actors, other than the entrepreneur, may succeed or fail to achieve effective performance or predictable outcomes.

This paper considers the entrepreneurial process as a soft system which is characterized by dynamic and interdependent relations between its stages, and assumes that the entire entrepreneurial process is organized in vertical and horizontal pattern, and with some circular movements in order to achieve the entrepreneur objectives (Bygrave \& Hofer, 1991).Such analogical views may help to understand the entrepreneurial process as a comprehensive system fragmented into stages involving interests, values, resources, activities, strategies, programs and participants. The interactions and communications between various social networks involved in all the entrepreneurial process in stages are featured by dynamic and interdependent relationships among them. This paper also considers the entrepreneurial process as an open-dynamic system which is influenced by political, social, psychological, economic, technological and cultural dimensions. It also argues that these broad analogical views may help build the theoretical framework which allows better understanding to what is really going inside and outside the black box of the entrepreneurial process and how the entrepreneur is granted the opportunity to find some deficiencies in the entrepreneurial process and its outcomes.

Having reviewed much of the academic literatures and the empirical studies relevant to the topic, the entrepreneurial process can be visualized as organized vertical stages including functions, actors, chances, motivations, values, events and resources. These stages must be achieved to give whole outcomes to the entrepreneurial process (Morgan, 2005). There is another view as presented in the entrepreneurial process literature - the networks approach which visualizes the entrepreneurial process as a set of ties and interactions between the entrepreneur and informal and formal actors networks that communicated in every horizontal entrepreneurial stage. Essentially, these activities must be achieved to produce the whole outcomes to the entrepreneurial process (Johnston, 1991).

We argue it is impractical to label characteristics of the entrepreneurial process as (structured-vertical stages) vs. (structured-horizontal networks) in order to draw a new theoretical framework for entrepreneurial analysis, because many contextual aspects of the 
entrepreneurial process may be missed, and may also reveal considerable resistance to innovations in the entrepreneurship analysis.

To avoid the dichotomous relationship between these two different perspectives, this paper suggests the system idea of dynamic and interdependency to combine the advantages of these perspectives in one theoretical framework for analysis gives a new understanding to the entrepreneurial process and its expected outcomes.

The paper is structured as a follow: first it provides short review of the literature on entrepreneurial stages and entrepreneurial networks approaches. It then progresses to link advantages of these different approaches with the greater system idea of dynamic and interdependency. Subsequently, Entrepreneurial Process Networks EPN is introduced as a theoretical framework for understanding and analyzing the entrepreneurial process. It then moves to introduce this new theoretical framework as a new direction for future entrepreneurial research.

\section{The Stages of the Entrepreneurial Process}

Most of the entrepreneurship researches are focused on influence of individual traits or, characteristics of entrepreneurs on creating business ventures rather than steps they must follow to create a successful business venture. In this context (Bygrave, 2004) argued that the best entrepreneurship ideas were profitable only because the entrepreneurs went through the necessary steps to build a company from scratch.

The entrepreneurial stages model is based on the idea that entrepreneurship is a complex phenomenon which is not shaped or implemented by an entrepreneur alone; it is the outcome of some sorts of actions, activities and interactions that occur between the entrepreneur and social networks (Chay, 1993).This model explains how the whole entrepreneurial process is fragmented down into functional stages and how each entrepreneurial stage follows another during the entrepreneurship life cycle (Bygrave, 2004). The whole explanations to the entrepreneurial process comes from collective decisions that are made by various participants who are involved in all entrepreneurial stages with the assumption that each stage is distinct in terms of its actors, activities, resources, knowledge, information and outcomes.

The entrepreneurial process in stages is equivalent to the strategic-oriented plan (Griffin \& Van der Linden 1998). It explains how the new business idea is discovered, evaluated, developed and implemented. Although the early stages of entrepreneurial process are sequential, sometimes, they may curve from linearity or might actually proceed in parallel (Swenson, 1992). For example, an entrepreneur may discover an opportunity and begins an evaluation, while he is developing a concept or new business strategy. He may also test the business model while he begins to execute the marketing plan. Yet, in the harvesting stage, the entrepreneur may continue to refine his basic idea, re-evaluate the opportunity and revise the business plan (Bygrave \& Hofer, 1991).

Entrepreneurial stages model could be a useful starting point for categorizing the entrepreneurial process as sequential stages involving various types of activities, events and strategies that are implemented to perform a successful business venture. 
A review of the entrepreneurship literatures assembled from the works of scholars such as: (Timmons, 1978; Bygrave, 2004; Shane \& Venkataraman, 2001; Brixy, Sternberg \& Stüber, 2008), have revealed that there are many ways to identify and recognize the process of creating a successful business venture. However, some other scholars have described the entrepreneurial process as equivalent to the product life-cycle, and explained that the entrepreneurial process is fragmented down into sequential functional stages featured by innovative practices. With large margins of agreement between scholars, there are some fundamental stages the entrepreneurial process must go through, these stages are:

1. Identifying an opportunity: the stage in which the entrepreneur generates idea, recognizes opportunity, and makes feasibility analysis to new product or service, and examines market by conducting surveys or questionnaires to understand the needs and preferences of consumers;

2. Concept development: in which, entrepreneur plans the venture, identifies needed resources, develops a business plan and selects strategies for penetrating the new markets ,or protects intellectual property rights;

3. Gathering resources: in which, the entrepreneur identifies the financial, human and material resources he really needed for starting the new venture, etc;

4. Actualization: in which, the entrepreneur establishes his venture and utilizes available resources in effective ways to achieve his objectives;

5. Harvesting: in which, the entrepreneur decides to continue and grow or, even demise his new idea.

Entrepreneurial process in stages appears to be as structural model, informs how every entrepreneurial stage and its outcomes are considered as an essential starting point to the next proceeding stage (Bygrave, 2004). It assumes that, identifying an opportunity stage and its outcomes affects the concept of the development stage and its outcomes, which in turn affects the activities of gathering resources stage and its outcomes and so on.

Considering Entrepreneurial Process as complete system which includes subsystems or stages directed in a vertical structure to generate maximum output from minimum inputs (Seng, 1990). It is valuable to note that stages model can help visualize entrepreneurship as a sequential process in stages which crosses institutional boundaries. It could also be a possible alternative to old entrepreneurial approach which focuses analysis on a single phenomenon such as individual traits or personal characteristics as unit of analysis (Van de VenVenkataraman, Polley \& Garud, 1989).

Aside from some positive effects mentioned above, there are many criticisms raised to the entrepreneurial stages model. It is a descriptive model which fails to provide clear relationships between the entrepreneur and the entrepreneurial process and attaches importance to the formal structure with no clear reference to informal relationships between participants involved in all entrepreneurial stages.

Furthermore, entrepreneurial stages theory focuses on the entrepreneur who generates the idea with little reference to other participants in the entire process. Despite that, the entrepreneurial 
stages model is criticized for being as a linear model as it fails to provide the complete framework for entrepreneurial analysis. The stages model could be useful to present the entrepreneurial process as a system fragmented into subsystems or functional stages, and allows examining every entrepreneurial stage and its outcomes from the perspectives of individuals or groups who govern its context.

\section{The Networks Approach to Entrepreneurial process Analysis}

Historically, the entrepreneurs have been the key players in the entrepreneurial process and their personal traits, characteristics and actions have been the unit of analysis to most entrepreneurship studies (Venkataraman, 1997). From the beginning of 1990s, the entrepreneurial networks approach has become a useful analytical tool to examine the collective ties or clusters of social networks which work together to find innovative solutions to the problems in democratic societies (Bhave, 1994). In a narrower sense, the entrepreneur seems to be an active networker who defines the people who may cooperate to launch his new business venture (Craig \& Lindsay, 2001).

Therefore, social actors' networks and the factors that open opportunities and risks, appear to be vital in analyzing of the entrepreneurial process. In this sense, formal and informal networks are two main analytical tools examine the set of entrepreneurs' networks which are connected by a set of social ties (Borgatti \& Foster, 2003). They visualize the roles of the entrepreneurs networks as not only related to early stages of business formation process, but also allowed to examine their activities throughout the process of creating a new business venture(Hoang \& Antoncic, 2003). The networks which constitute an important instrument provide the entrepreneur with important resources such as the money, human capital and information and knowledge he needed to create successful business venture (Jashapara, 2011).

Entrepreneurial network analysis has increased in importance due to the emerging insights pointing that the outcomes of entrepreneurial process are generated from the iterative interactions between the entrepreneur and formal and informal actors' networks (Bygrave, \& Hofer, 1991). Networks approach can be a useful analytical tool which permits researchers to examine new venture creation process from different perspectives and allows them to go beyond the mere description of formal entrepreneurial structure or traditional entrepreneurial stages view (Westhead \& Batstone, 2000). Furthermore, the networks approach helps researchers to examine various networks that control decisions in each entrepreneurial stage (Laumann \& Pappi, 1976).

In entrepreneurial research, the networks approach can be a useful analytical tool that attracts researchers' attentions to collective ties between the entrepreneur and customers, suppliers, public, profit and non-profit organizations. It also guides researchers to look at the entrepreneurial process as a new structure of governance characterized by predominance of informal interactions, horizontal as opposed to a hierarchical structure of relationships between entrepreneurial actors (Raue \& Wieland, 2015). Since collective activities and decisions of entrepreneurial process are resulted from entrepreneur partnerships with others in each horizontal stage, it becomes clear the process may curve from the vertical structure of governance. 
The networks approach examines how the central positions of an entrepreneur and other partners as well as influence of social, economic, political, technological and cultural factors on the entrepreneurial process and its outcomes. It also assumes that any change in any factor may influence the structure of power relations between the entrepreneur and the various partners (Josef \& Peter, 1998). For example, the recent changes in economic theory have moved analysis from entrepreneur traits to entrepreneurial process, in which entrepreneur acts as an active facilitator to the process of creating something new, or added values to what is called knowledge economy (Jashapara, 2011).

Therefore, collective activities, decisions of entrepreneurs' networks and influences of external contexts on the entrepreneurial process and its outcomes motivate researchers to analyze the process from different perspectives.

At the center of entrepreneurial process analysis, the networks approach is not attributable to gender, social status, political affiliation, religious beliefs, ethnicity, or the psychological predisposition of entrepreneurs. Rather, it is attributable to clusters of social and economic relations between the entrepreneur and the informal and formal networks involved in all stages of the entrepreneurial process, and explains why and how they behave and under what circumstances (Carpenter, Esterling \& Lazer, 1998).

Aside from some positive effects mentioned above, many criticisms were raised against networks approach. It can be a descriptive model which fails to build strong hypothetical relationship between the entrepreneurial process and entrepreneurial networks. The networks approach emphasis is on passing entrepreneurial decisions between entrepreneur and actors networks at the same entrepreneurial stage (horizontal), and ignores the view that the entrepreneurial process is contextual and dynamic from the stage of identifying an opportunity to the harvesting stage.

Additionally, the networks approach does not explain how entrepreneurial networks existing in the next entrepreneurial stage are influenced by the activities and outcomes of previous stages. However, the networks approach focuses on the dominant entrepreneurs' networks as unit of analysis and neglects the view that the process of creating new business cannot be controlled by any individual groups (Emirbayer \& Goodwin, 1994).

\section{Discussion}

\section{Gaps in methodology}

Drawn from above mentioned literatures, whether entrepreneurial stages approach or networks approach ignored many aspects of the entrepreneurial process, and failed to provide theoretical relationships between the entrepreneurial process and various social networks that involved in entrepreneurial stages. Furthermore, entrepreneurial stages approach is focused on the entrepreneur who dominates decisions of entrepreneurial stages (as unit of analysis), while the entrepreneurial networks approach is focused on a cluster of ties between informal groups that dominate each horizontal stage. In general, both perspectives ignore the idea that the entrepreneurial process can be seen as the complete system characterized by dynamic and 
interdependence relations between its stages which stretch from identifying an opportunity to the harvesting stage.

To bridge the gap between entrepreneurial stages approach and networks approach, we have assumed that both perspectives complement each other and each approach counteracts the worst features of another. The paper suggests the system idea of dynamic and interdependency to bring advantages of both approaches in one framework for analysis provides a comprehensive understanding to the whole entrepreneurial process and its outcomes.

Before building a new theoretical framework for entrepreneurial analysis, it would be helpful to give a brief discussion of the system idea of dynamic and interdependency as a basis for entrepreneurial analysis.

\section{System Ideas of Dynamic and Interdependency as Basis for Entrepreneurship Analysis}

In a broader sense, the system ideas are founded on some basic universal principles that help us detect all aspects of our real life and many other natural phenomena, once we learn more how to perceive them (Emirbayer, \& Goodwin, 1994). In a narrower sense, the system idea attempts to make reliable inferences regarding the subsystems behavior and basic structures and the patterns of dynamic and interdependence relationships between them (Patricia Werhane, 2008).

The system approach which emphasizes on the whole system rather than its fragmented parts can be a useful perspective to identify the structural flaws that hinder soft system performance. It may also help us understanding why the entrepreneurial process as a system characterized by dynamic and interdependent movements between its parts may fail to produce effective performance, or expect outcomes to the whole entrepreneurial process (Seng, 1990). Even if we suppose that an entrepreneurial process as a soft system which may fail to predict accurate outcomes, it still gives more elucidation to social and economic realities that are inherent in the entrepreneurial process.

In this context, system idea characterized by dynamism and interdependency between its parts may help us to understand what is really going inside the entrepreneurial process black box, and encourages to identify problems in fundamental structures of social and economic interactions between the entrepreneur and the formal and informal networks that are involved in all stages of entrepreneurial process (Carpenter, Esterling \& Lazer, 1998). The system approach that emphasizes on whole system rather than its individual parts has made this approach commonly used to find solutions to many problems in different fields such as business, organizational learning and public policy (Yeatman, 1998).

The system idea focuses on the dynamic and interdependent relationships between system parts which move in vertical, horizontal and circular patterns in order to attain the expected outcomes to a specific social phenomenon (Shane \& Venkataraman2000). System thinkers argue that even if a system can work under uncertain circumstances, which sometimes make it behave unexpectedly, the system maintains its stability and self- correction. They also argue that a dysfunction of system performance is resulted from its whole behavior rather than its individual parts (Rapport, 1986). 
The theoretical and practical studies of dynamics and interdependencies may also help us understand the structural relationships between the system parts that work together to achieve the expected outcomes (Seng, 1990).

According to the system view, the entrepreneurial process is comprised of five sequential stages, or vertical dynamic subsystems, in which an entrepreneur and formal and informal networks are connected with each other in order to produce new things to each entrepreneurial stage. The activities and outcomes of every entrepreneurial stage affect the activities and outcomes of the following stage, and in total these stages are giving accumulated outcomes to the whole entrepreneurial process.

Considering the entrepreneur as an active builder to the entrepreneurial networks with whom he may cooperate to find solutions for the creation of his new venture. Such view may enhance our understanding to the actions of entrepreneurial networks involved in each entrepreneurial stage, and how their members may look to themselves as being as important holders to resources, skills, knowledge, advices, wisdoms and values which are seen critical to others who may join to the next entrepreneurial stages (Borgatti \& Cross, 2003). Thus, it becomes clear that whether an entrepreneur or formal or informal actor networks that involve in all entrepreneurial stages are equally responsible for the good or ill performance of the entrepreneurial process and not the entrepreneur alone.

We argue that such analogical views to the entrepreneurial process as the dynamic and interdependence soft system may help the researchers to detect the strengths and weaknesses in the structural relationships between the entrepreneur and the social networks that are involved in whole entrepreneurial process. Furthermore, these analogical views may also help researchers to unmask the social and economic realities that inherent in the process of creating successful business venture or it even seem better than using complex studies of the risk analysis.

\section{The Combined Approach of the Entrepreneurial Stage and the Entrepreneurial Networks}

To distance current entrepreneurship researches from trapping between the two opposed perspectives - the entrepreneurial stages (vertical) vs. the entrepreneurial networks (horizontal), this paper is proposed to bring the advantages of these different perspectives together, and embrace the fact that they complement each other and offer new comprehensive insights to the entrepreneurial analysis (Linder, Stephen, Peters \& Guy, 1989).

The proposed theoretical framework here is based on using the benefits of the soft system idea, characterized by the dynamic and interdependent relationships between its interrelated parts. Our intention is to produce a comprehensive theoretical framework for the entrepreneurial process, with the assumption that the entrepreneurial process in stages and the entrepreneurial networks are oriented and connected in vertical and horizontal and circular movements to give accumulated outcomes to the whole entrepreneurial process (Morgan, 2005).

Thus, Entrepreneurial Process Network as the new theoretical framework for understanding and analyzing the entrepreneurial process is derived from combining advantages of the 
entrepreneurial stages approach and the entrepreneurial networks approach which located within larger system idea of dynamism and interdependency.

The entrepreneurial process networks, which forms the conceptual framework for understanding the entrepreneurial process is focused on five major entrepreneurial stages namely; identifying an opportunity, concept development, gathering resources, actualization and harvesting, as well as the activities and strategies adopted by entrepreneurs and formal and informal networks involved in all entrepreneurial stages. Considering the entrepreneurial process as a unitary dynamic and interdependent system may help the entrepreneur detect the strengths and weakness of the entrepreneurial process, and then suggest some possible solutions that might help improve its structure and performance (Rhodes, 1990).

In this context, it is worth making a major distinction between the system idea and the entrepreneurial process networks approach. The system idea is a methodology focusing researchers' attention on dynamic and interdependent relationships between the entrepreneurial stages and actors networks that communicate and interact in these entrepreneurial stages under uncertain circumstances to produce expected outcomes of the whole entrepreneurial process. However, the entrepreneurial process networks as framework goes further to examine the inherent realities and activities of the entrepreneur and the formal and informal networks that are involved in every entrepreneurial stage and its context (Westhead \& Batstone, 2000).

\section{The Entrepreneurial Process Networks Framework}

Considering an entrepreneurial process as a soft social system in which every entrepreneurial stage follows another, and the activities and interactions between entrepreneur and the formal and informal networks involved in these stages give accumulated outcomes to the whole entrepreneurial process. Entrepreneurial process networks as framework for analysis examines the social and economic realities inherent in all entrepreneurial stages which stretch from identifying an opportunity to the harvesting stage. It assumes that interactions between an entrepreneur and actors networks involved in each entrepreneurial stage are featured by collaborative efforts rather than competitive relations (Jashapara, 2011). Even though we examine each entrepreneurial stage in terms of its activities, participants and outcomes are separate. The bigger picture of the whole entrepreneurial process always remains in mind. Generally, the entrepreneurial process networks framework for entrepreneurial analysis can be expressed as follows:

1. The entrepreneurial process involves all functions, activities and actions associated with the perception of transforming an idea into a fully fledged firm.

2. The entrepreneurial process is composed of functions that are fragmented down into vertical steps in order to achieve desirable ends, which are the entrepreneurial stages.

3. The entrepreneurial process collects different actors, including the entrepreneur himself, and informal and formal groups who act and communicate in a horizontal integration in order to achieve desirable ends, which describes the entrepreneurial networks. 


\section{Macrothink}

4. The system idea of dynamic and interdependency is suggested to combine advantages of the entrepreneurial stages (vertical) and the advantages of the entrepreneurial networks (horizontal) in a larger framework of analysis, which is the entrepreneurial process networks.

5. The entrepreneurial process networks as framework for analysis can be utilized to reveal what happens in every entrepreneurial stage and its context.

6. Activities of all actors networks are involved in all entrepreneurial stages and their contexts give an accumulated outcomes to the whole entrepreneurial process.

7. The entrepreneur can proceed to detect the strengths and weaknesses in the whole entrepreneurial process and propose possible solutions that might help improve its structure and outcomes.

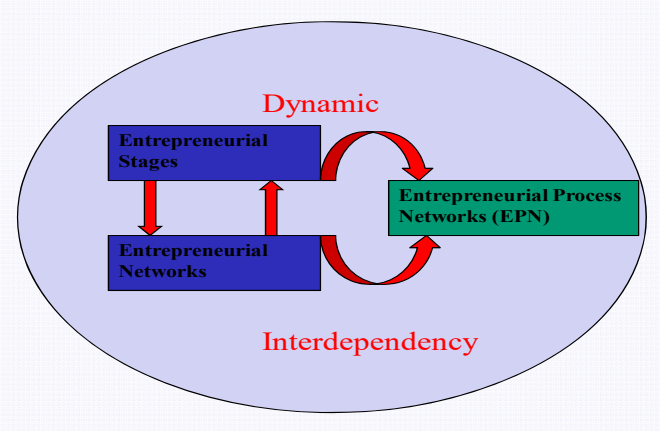

Figure 1. depicts the proposed ENP framework 


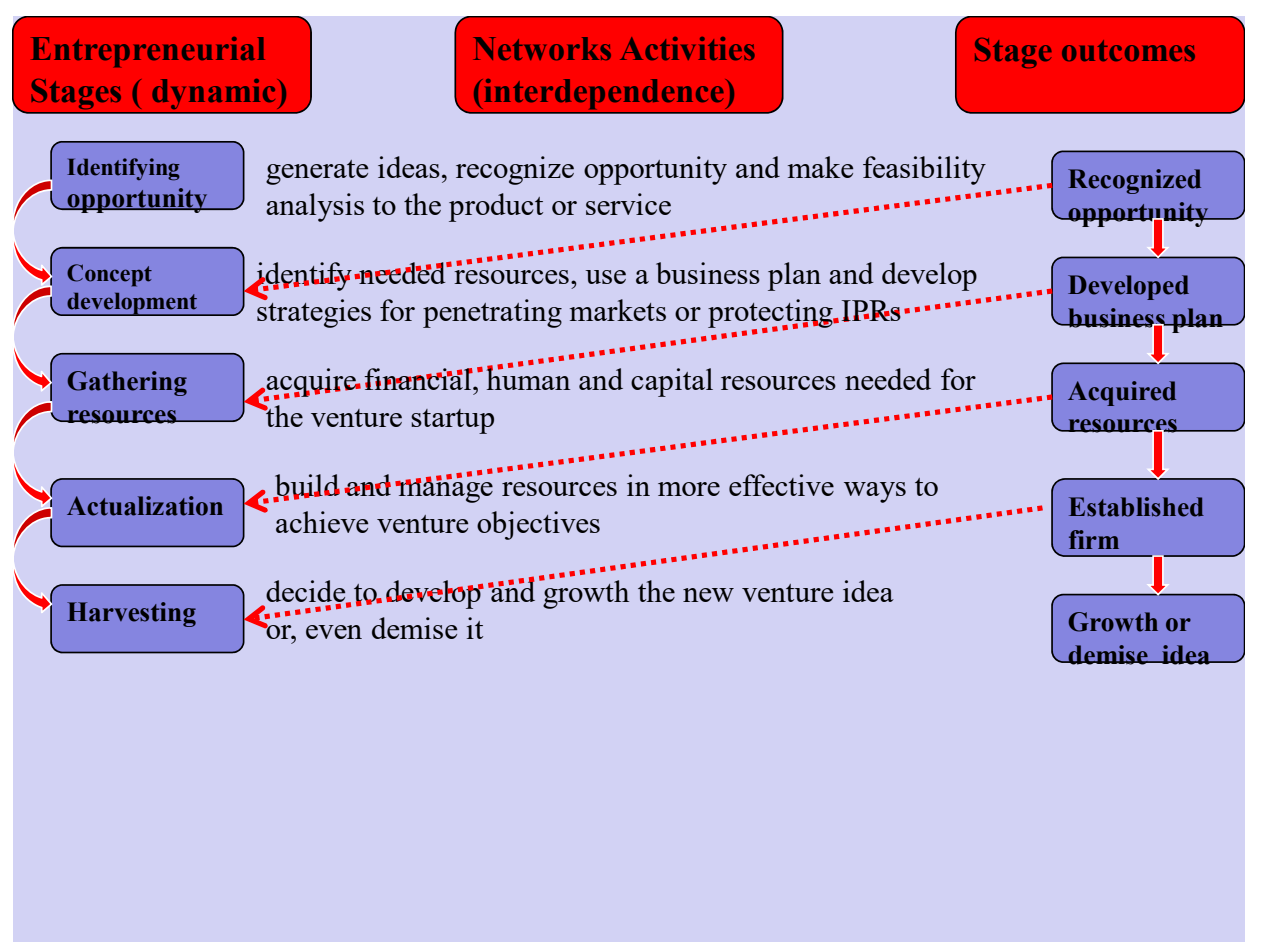

Figure 2. ENP for analyzing entrepreneurial process

\section{Conclusions and Perspectives}

Most entrepreneurship studies are dual in nature as they neglect the aspects of dynamic and interdependence between entrepreneurial process and its stages. The researchers' contributions to current entrepreneurship literature taking the economic and psychological and sociological perspectives have approved inadequate, because of failing to clear the relationships between causes and consequences of the entrepreneurial process. They also do not provide entrepreneur with a roadmap to follow or, a logical model for starting his new business venture. Alternatively, this study has suggested the system idea of dynamic and interdependency as a comprehensive methodology which mediates between causes and consequences and allows the entrepreneur to look in a more logical way to the whole entrepreneurial process and its outcomes.

Integrating both perspectives, the entrepreneurial stages and entrepreneurial networks with the system ideas of dynamic and interdependency may help to connect between entrepreneurial process and its fragmented stages and offer new framework for understanding the whole entrepreneurial process and its accumulated outcomes. More specifically, the framework of Entrepreneurial Process Networks which form a basis for analysis, enables researcher to unmask the coherent realities that dwell inside every entrepreneurial stage, and allows identifying weaknesses in the structural relationships between entrepreneur and formal and informal networks that govern every entrepreneurial stage and its context. 


\section{Recommendations for Future Research}

Based on reviewing many academic literatures and research methods, the entrepreneurship researches are still borrowing many methods and theories from different disciplines. These gaps in methodology have left entrepreneurship phenomenon with no real meaning, or clear entity yet (Leo Paul, Teresa \& Dana, 2005). This paper has developed a comprehensive model to integrate the new theoretical arguments in entrepreneurship areas where literatures, researches and methods show that they are lacking. To some extent, it is believed that system approach idea of dynamic and interdependency may bridge the gaps in methodology and connect between entrepreneurial stages and their outcomes.

Generally, entrepreneurial process have two distinct theories, the entrepreneurial stages and networks which explain how and why various activities occur in all entrepreneurial stages may structure in vertical, horizontal and circular movements to produce expected outcomes to the whole entrepreneurial process. In just the same way, entrepreneur organizes the new business venture through series of actions in stages, and at any time. He exploits available resources and activities of different participants to set a new governance structure to the whole entrepreneurial process.

Based on the use of system idea of dynamic and interdependency, and the EPN which form the basis for entrepreneurial analysis, the following requirements should be taken in considerations when researchers conduct future research:

- They must be compatible with the ideas and principles of economics, psychology, sociology, management and organizations to enable theorizing entrepreneurial process as the complete soft social system.

- They must integrate and control the process of analysis by using the system idea of dynamic and interdependency, and focus on elements of the entrepreneurial process or its subsystems (functional stages and formal and informal networks) without losing the links to the whole entrepreneurial process.

- They must recognize the formation of functional stages and identify the flow of information and communications between entrepreneur and social networks involved in all entrepreneurial stages.

- They must provide a common language to describe all aspects of the entrepreneurial process in stages as accumulative outcomes.

- The EPN framework may provide structural and operational bases about the ways in which entrepreneur can create and pursue successful business venture.

To some extent, the use of EPN framework will add new literature to entrepreneurial process and open new opportunities for future research related to the roles of formal and informal networks in creating successful entrepreneurial process. EPN allows representing social realities that reside in every entrepreneurial stage and assists entrepreneur to predict its activities and outcomes. Therefore, additional studies are needed to reveal the new structure of entrepreneurial governance. Finally, the EPN framework, in a short term, will be tested by a 
new research run by the author who will make a preliminary assessment to the strengths and weakness of his proposed framework, and point to some uncovered areas.

\section{References}

Bhave, M. P. (1994). A process model of entrepreneurial venture creation. Journal of Business Venturing, 9, 223-242. http://dx.doi.org/10.1016/0883-9026(94)90031-0

Borgatti, S., \& Cross, R. (2003). A relational view of information seeking and learning in $\begin{array}{llll}\text { social networks. } & \text { Management 432-445. }\end{array}$ http://dx.doi.org/10.1287/mnsc.49.4.432.14428

Brixy, U., Sternberg, R., \& Stüber, H. (2008). From potential to real entrepreneurship, IAB-Discussion Paper.

Bygrave, W. (2004). The entrepreneurial process, Hoboken, NJ: John Wiley \& Sons.

Bygrave, W. \& Hofer, C. (1991). Theorizing about entrepreneurship. Journal of Entrepreneurship Theory and Practice, 16(2), 13-22.

Carpenter, D., Esterling, K., \& Lazer, D. (1998). Strength of Weak Ties in Lobbying Networks. Journal of Theoretical Politics, 10, 417-444. http://dx.doi.org/10.1177/0951692898010004003

Casson, M. (2010). Entrepreneurship - Theory, Networks, History, Massachusetts.

Chay, Y. (1993). Social support, individual differences and well-being. Journal of Occupational and Organizational Psychology, 4, 286-303.

Churchill, N. \& Lewis, V. (1983). The five stages small business growth. Harvard Business Review, 3, 30-46.

Emirbayer, M., \& Goodwin, J. (1994), Network Analysis, Culture, and the Problem of Agency. American Journal of Sociology, 9, 141-154. http://dx.doi.org/10.1086/230450

Gartner, W., Shaver, K., Carter, N., \& Reynolds, P. (2004). Handbook of Entrepreneurial Dynamics, California: Sage Publications Inc.

Griffin, L., \& Vander, L. (1998). New Methods for Social History, Cambridge: University of Cambridge Press.

Greiner, L. (1998). Revolution as organizations grow. Harvard Business Review, 3, 55- 66.

Hoang, H \& Bostjan, A. (2003), Network-based research in entrepreneurship. Journal of Business Venturing, 18, 165-187. http://dx.doi.org/10.1016/S0883-9026(02)00081-2

Johannisson, B., Alexanderson, O., Nowicki, K., \& Senneseth, K. (1994). Entrepreneurs in Contextual Networks. Entrepreneurship and Regional Development, 6, 329-356. http://dx.doi.org/10.1080/08985629400000020

Jashapara, A. (2011). Knowledge Management: An integrated Approach, Pearson Education Limited, Essex England. 
Josef, B., \& Peter, P. (1998). Network Support and the Success of Newly Founded Business. Small Business Economics, 10, 213-225. http://dx.doi.org/10.1023/A:1007997102930

Kelley, D., \& Marram, E. (2004). Managing a growing business, Hoboken, NJ: John Wiley \& Sons.

Kirzner, I. M. (1979). Perception, Opportunity, and Profit: Studies in the theory of entrepreneurship, Chicago: University of Chicago Press.

Laumann, E. ,\& Pappi, F. (1976). Networks of Collective action: A perspective on community influence systems, New York, Academic Press.

Leo, D., \& Teresa E. (2005). Expanding the scope of methodologies used in entrepreneurship research. International Journal of Entrepreneurship and Small Business, 2(1).

Linder, Stephen, Peters, \& Guy. (1989). Instruments of Government: Perception and Contexts. Journal of Public Policy, 9, 35-58. http://dx.doi.org/10.1017/S0143814X00007960

McClleland, D. (1961). The achieving society, Princeton, NJ: Van Nosstrand. http://dx.doi.org/10.1037/14359-000

Morgan, P. (2005). The Idea and Practice of System Thinking and Their Relevance for Capacity Development, European Centre for Development Policy Management.

Muzyka, D., de Koning, A., \& Churchill, N. (1997). Building the entrepreneurial corporation. Sites:insead.edu/facultyresearch/research/doc.cfm?did $=46644$.

Patricia, H. (2008). Mental Models, Moral Imagination and System Thinking in the Age of Globalization. Journal of Business Ethics, 78(3), 463-474. http://dx.doi.org/10.1007/s10551-006-9338-4

Rapport, A. (1986). General System Theory: Essential Concepts \& Applications. Cambridge, Mass: Abacus Press.

Raue, J., \& Wieland, A. (2015). The interplay of different types of governance in horizontal cooperation's. The International Journal of Logistics Management, 26(2). http://dx.doi.org/10.1108/IJLM-08-2012-0083

Rhodes, R. (1990). Policy Networks: A British Perspective. Journal of Theoretical Politics, 2(3), 293-317. http://dx.doi.org/10.1177/0951692890002003003

Schumpeter, J. (1961). A Theory of Economic Development, Oxford University Press.

Seng, P. (1990). The Fifth Discipline: The Art and Practice of Learning Organization, New York, Doubleday.

Shane, S. (2004). Academic Entrepreneurship, University Spinoffs and Wealth Creation, Cheltenham: Edward Elgar. 


\section{Macrothink}

Journal of Management Research

ISSN 1941-899X

2016, Vol. 8, No. 3

Shane, S., \& Venkataraman, S. (2000). The Promise of Entrepreneurship as a Field of Research. The Academy of Management Review, 25(1), 217-226. http://dx.doi.org/10.5465/amr.2000.2791611

Shane, \& Venkataraman. (2001). Entrepreneurship as a Field of Research. Academy of Management Review.

Swenson, R. (1992). Order, Evolution and Natural Law: Fundamental Relations in Complex System Theory, New York, NY: Marcel Dekker, pp.125-147.

Timmons, J. (1978). Characteristics and role demands of entrepreneurship. American Journal of Small Business, 3(1), 5-17.

Van de Ven, A. Ven kataraman, S., Polley, D., \& Garud, R. (1989). Processes of new business creation in different organizational settings, New York: Harper/Ballinger.

Venkataraman, S. (1997). The distinctive domain of entrepreneurship research, Greenwich, CT: JAI Press.

Westhead, P. Batstone, S., \& Frank, M. (2000). Technology-Based Firms Located on Science Parks. Enterprise and Innovations Management Studies, 1(2).

Yeatman, A. (1998). Activism and the Policy Process, Allen \& Unwin 